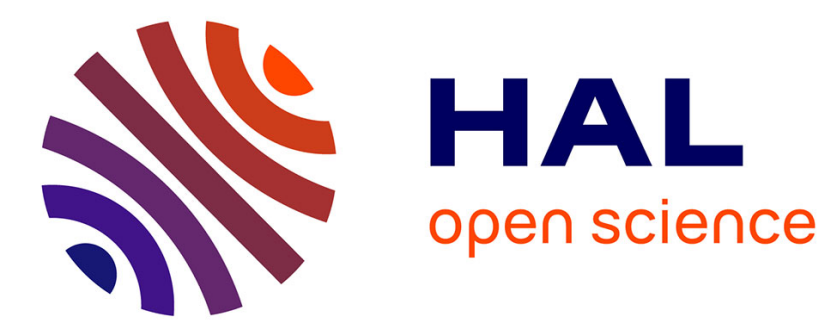

\title{
Process Classes Deployed in Manufacturing Enterprises
} Richard Henry Weston, Alejandro Guerrero, Kamran Ali Chatha

\section{To cite this version:}

Richard Henry Weston, Alejandro Guerrero, Kamran Ali Chatha. Process Classes Deployed in Manufacturing Enterprises. International Journal of Computer Integrated Manufacturing, 2007, 20 (06), pp.505-523. 10.1080/09511920600863031 . hal-00513381

\section{HAL Id: hal-00513381 https://hal.science/hal-00513381}

Submitted on 1 Sep 2010

HAL is a multi-disciplinary open access archive for the deposit and dissemination of scientific research documents, whether they are published or not. The documents may come from teaching and research institutions in France or abroad, or from public or private research centers.
L'archive ouverte pluridisciplinaire HAL, est destinée au dépôt et à la diffusion de documents scientifiques de niveau recherche, publiés ou non, émanant des établissements d'enseignement et de recherche français ou étrangers, des laboratoires publics ou privés. 


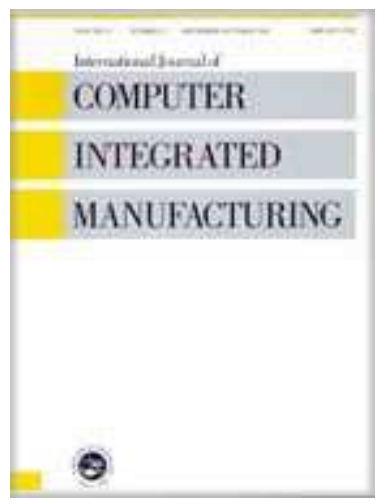

\section{Process Classes Deployed in Manufacturing Enterprises}

\begin{tabular}{|c|c|}
\hline Journal: & International Journal of Computer Integrated Manufacturing \\
\hline Manuscript ID: & TCIM-2006-IJCIM-0039.R1 \\
\hline Manuscript Type: & Original Manuscript \\
\hline $\begin{array}{r}\text { Date Submitted by the } \\
\text { Author: }\end{array}$ & 07-Jun-2006 \\
\hline Complete List of Authors: & $\begin{array}{l}\text { Weston, Richard; Loughborough University, Wolfson School of Mech } \\
\text { \& Man Eng'g } \\
\text { Guerrero, Alejandro; Loughborough University, Wolfson School of } \\
\text { Mech \& Man Eng'g } \\
\text { Chatha, Kamran; Lahore University of Management Sciences, } \\
\text { Suleman Dawood School of Business }\end{array}$ \\
\hline Keywords: & BUSINESS PROCESS RE-ENGINEERING, PROCESS MODELLING \\
\hline Keywords (user): & Complex Organisations, Organisation Design \\
\hline
\end{tabular}

\section{s ScholarONE" \\ Manuscript Central}




\title{
Process Classes Deployed in Manufacturing Enterprises
}

\author{
R H Weston, A Guerrero and K A Chatha \\ MSI Research Institute, Loughborough University
}

\begin{abstract}
Previous authors have classified process types found in Manufacturing Enterprises (MEs). This paper considers common and distinctive features found amongst these classifications, which govern their utility and completeness. Based on understandings gained about their collective features and shortcomings the paper argues a case for a unified classification of process types. Such a classification is presented and its applicability is discussed and exemplified.

Keywords: Complex Organisations, Process Classification, Business Process Change, Organisation Design,
\end{abstract}

\subsection{Introduction}

Much interest world-wide is centred on 'process thinking' and 'process modelling' as means of conceptualising and explicitly representing flows of activity in complex organisations needed to realise products and services for customers and values for stakeholders. Vernadat (1996) states that "processes represent the flow of control in an enterprise"; they constitute "a sequence of enterprise activities, execution of which is triggered by some event"; "most processes have a supplier of inputs and all have a customer using outputs". Scheer (1994) emphasised the dynamic nature of decision and action making about processes, with respect to (i) the need to transform material (physical) and informational (logical) entities, and (ii) resource allocation and the design of information systems. Weston (1996) observed that (a) process models are a conceptualisation of actions needed to achieve real-world transformations within finite time frames, (b) different process types involve different actions, or order actions differently, so as to achieve alternative real-world transformations, during a given process instance, and (c) commonly multiple instants of processes are realised so as to repetitively achieve similar real-world transformations over extended timeframes that can be considered to constitute the useful process lifetime.

Chatha et al (2006) distinguished between two schools of thought on processes and aligned these with so called 'systems engineering' and 'business' viewpoints. The definitions of Vernadat (1996) and Weston (1996) are aligned to the systems engineering viewpoint because they view the prime purpose of process models as being to define enterprise (and thereby enterprise system) requirements. This school of thought assumes that requirements models should be centred on explicit descriptions of activity flows, that can naturally be semantically enriched by attaching those 
precedence and decision making relationships, and related control, information and exception flows, needed to govern the execution of specific process instants. Chatha et al (2006) refer to such an enriched process model as being a 'process logic specification'; in that it explicitly describes temporal and causal dependencies linking elements of a process and thereby defines the flow of activities that need to be carried out to achieve the purpose of that process. Fundamental to the systems viewpoint about processes is a conceptual separation of 'process requirements' (i.e. the process logic) from 'models of candidate system solutions'. This is because conventionally the job of systems engineers is to analyse and choose between alternative ways of realising specified requirements. In the case of realising ME processes, potentially viable candidate systems will be some configuration of human and technical resources that collectively have the abilities (capabilities, competencies and capacities) to accomplish needed instances of the defined process logic within defined time-frame, cost and quality of service constraints (Vernadat 1996 and Ajaefobi et al 2006).

Business viewpoints about processes have been conceived in relation to concepts like Business Process Re-engineering (BPR) (Al Mashari and Zairi 1999), Change Management (Craig and Douglas 1997), Supply Chain Management (Brahm and Kleiner 1996), JIT (Imai 1986), LEAN (Warnecke 1993), Agile (Pine 1993), Value Stream Mapping (Drucker 1990) and Cost Engineering (Neely et al 1995). Typically these business concepts are facilitated by notions about Business Processes (BPs) that implicitly bind together descriptions of 'requirements' (what needs to be done) with 'solutions' (how it is done by a particular configuration of human and technical resources); thereby enabling the 'values generated' by processes, 'process operation times' and 'processing costs' to be enumerated.

To cater for differences in perception, in the remainder of this paper the terms 'process model', 'process type', 'process instant', 'process lifetime' and 'process logic' will implicitly be aligned to the systems (i.e. requirements) viewpoint about processes, whereas the term 'Business Process' (or BP) will be aligned to business school thinking (which couples requirement and solution viewpoints). Figure 1 further illustrates differences between 'systems engineering' and 'business school' viewpoints about processes and gives some simple examples and related definitions.

In recent decades important outcomes from business school and systems engineering research have been concepts, methods and techniques that can be used to improve the operation of specific 'networks of processes' deployed by Manufacturing Enterprises MEs. Amongst these outcomes are: published methods of realising (large and small scale) business process change; enterprise and process modelling methodologies and architectures that help decompose and formally represent generic and specific process networks; and reference models of common processes found in MEs. 
This paper focuses on the utility and completeness of published process classifications with a view to improving upon the existing provision of ME reference models.

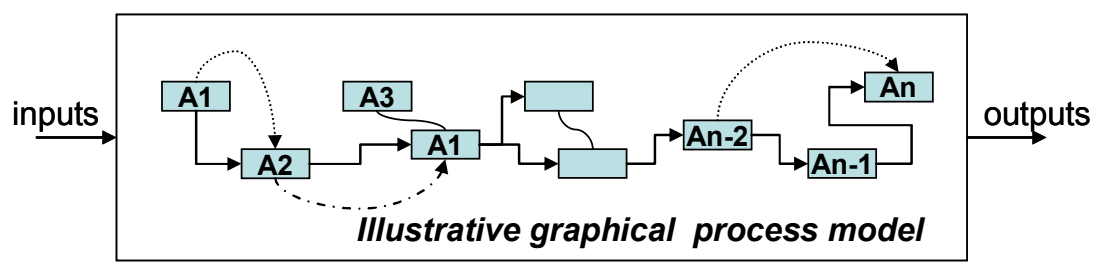

'process'- ordered set of activities

'process logic'- a conceptualisation of causal and temporal dependency relationships

that lend order to the execution of elemental activities that comprise a process

NB: causal and temporal dependencies can take many forms. For example an activity may only be required to execute (i.e. an action should only occur) if an event (such as the arrival of a works order) and defined conditions have occurred (e.g. sufficient raw material is available)

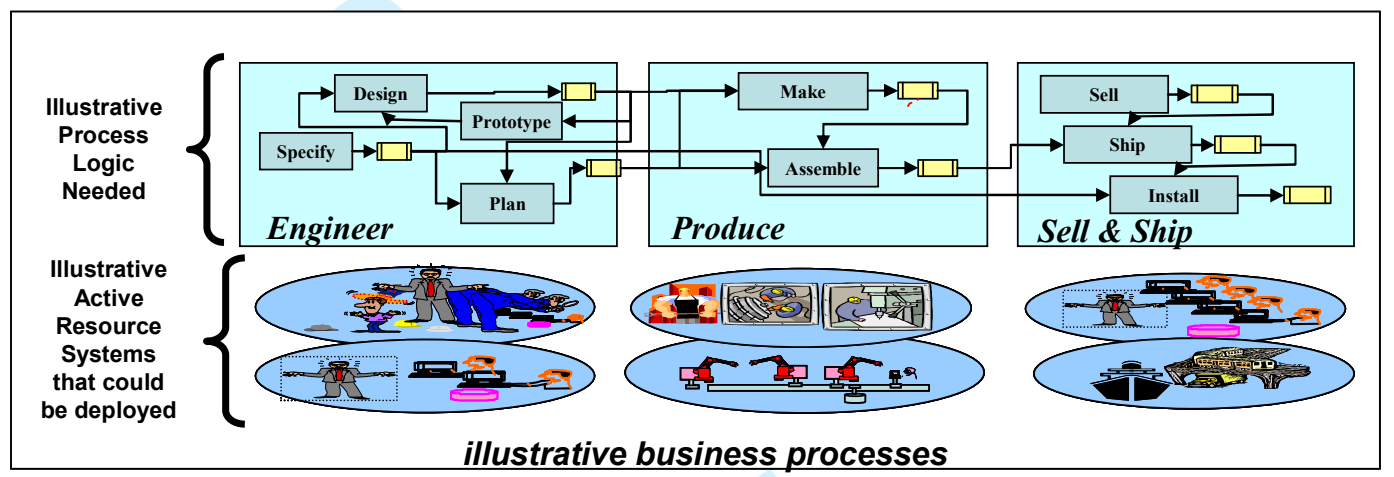

'business process'- encompass BOTH the 'process' (conceptualised as a ordered set of activities) and needed 'resource systems' (with needed abilities to realise the process)

'active resource systems'- comprise human \& technical resource elements (i.e. people, computers $\&$ automated machines) that have competencies \& capabilities to 'act' in a manner that accomplishes the activity set specified

NB: resource systems need to have embedded functionality, i.e. the potential (as and when required) to function in a way

that achieves defined activities, such as to 'turn parts', 'assemble parts', 'process orders', 'negotiate \& win contract's etc.

Figure 1 Some Process Definitions and Examples

The next section of this paper considers the structure and elements of six published process classifications, each of which identifies process types commonly deployed by MEs. This provides a basis for (a) reviewing common and distinctive features of each classification and (b) proposing the structure and elements of a unified process classification.

Section 4 proposes and describes such a unified model which in principle can be used flexibly by

(A) All classes of ME personnel: to create theoretic mental models of what MEs need to do (long, mid and short term), so as to position what they or their particular ME does relative to their mental model and thereby to improve their understandings such that they realise (collective and individual) responsibility assignments (be that of a managerial, engineering, support or operational) nature in more effective and timely ways.

(B) Other researchers and their students: to gain improved conceptual and holistic understandings about the purposes of MEs and how their purposes can naturally be decomposed into a network of processes. 
Subsequently section 5 illustrates important potential uses of the unified process classification, namely in support of strategy realisation in MEs. Also related to this illustrative use is a discussion about the use of different forms of process modelling technique.

\subsection{Review of Process Classifications}

\subsection{Pandya et al's 12 generic business processes}

Pandya et al (1997) observed twelve distinctive types of Business Process (BP) claiming that they typified most European manufacturing businesses. Figure 2 depicts the BP types identified and their affiliation to one of three process classes, namely 'generic operate', 'generic support' and 'generic management' groupings. Pandya et al explained that normally specific BPs within each type and class are conceived and developed over time in a similar manner to that of functional ME groupings that give rise to manufacturing, design, sales, finance, etc functional affiliations and related organisation boundaries. These authors point out that a process focus, rather than an organisational or functional focus, can (a) improve collective working in MEs and (b) help identify values generated and costs incurred when activities (and groups of activities) are realised. Pandya et al's (1997) descriptions of their three main process classes are paraphrased by the following.

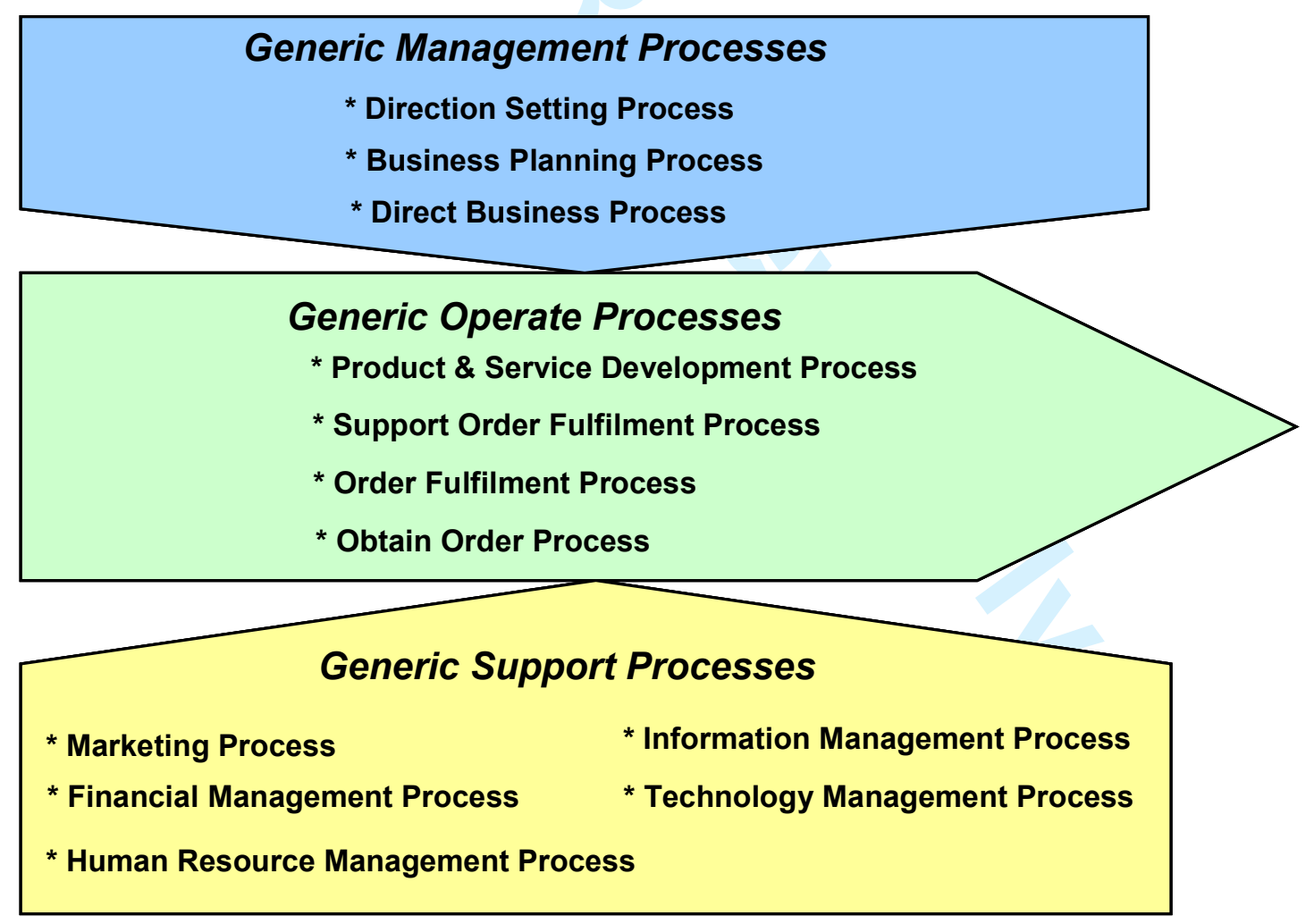

Figure 2 Pandya et al's (1997) Process Classification 
Generic operate processes: encompass four main BP types that directly generate values for customers. It follows that the main purpose of BPs belonging to the 'generic operate process class' is to realise products and services that satisfy customer requirements.

Generic support processes: are 'infrastructural BPs' needed to facilitate the operation (and interoperation) of BP types belonging to the 'operate' and 'management' process class. Pandya et al state that BPs belonging to the generic support class can be 'pure processes' or 'hybrids of processes and functions'. Further they state that specific instances of support BPs may not have a definitive beginning (when execution commences), body (during which execution occurs) and end (when execution ceases). For example, some inspection and reporting processes may occur continuously, without a clear distinction between process instances.

Generic management processes: are commonly embedded onto other BP types. Although these process types are not considered to directly add value for customers, instances of management BPs are necessary to coordinate efforts of (human and technical) resources; so as to ensure that BP types belonging to the generic operate and generic support classes run in an efficient, timely, effective and robust manner over short, medium and long timeframes. Pandya et al distinguished between three management BP types by virtue primarily of the planning and operation time frames with which they are concerned. All three management BP types typically constitute mainly information processing and decision-making activities.

\subsection{BS ISO-14258 and Activity Classification}

BS ISO-14258 (1998) specifies a way of classifying processes with respect to 'phases' in the lifetime of MEs. The approach taken is to classify 'prime activities' carried out in MEs within the groupings: 'what-activities', 'how-activities' and 'do-activities'. Here it was assumed that 'whatactivities' are concerned mainly with strategic issues, focused for example on deciding what kinds of products the ME should realise, and what product markets the ME should be competitive in. 'How-activities' mainly address more tactical concerns, for example they may decide "how things can or should be done". Whilst 'do-activities' are those ME activities needed to do all activities required (typically on a repetitive basis) to generate products and services for customers.

An underpinning notion of ISO-14258 is that despite the need in any specific organisation to carry out a very large number of specific context dependent activities, abstractions of those activities can be classified with respect to the time span of their (planning and operating) concerns; i.e. whether they are concerned mainly with achieving strategic, tactical or operational objectives and goals.

The ISO14258 classification focuses mainly on lifecycle aspects of MEs and their products. While the Pandya et al classification has a prime focus on the purpose of activity groupings. On the other 
hand, as illustrated by Table 1, specific actions (and implied specific orderings of actions) carried out in a particular ME can be 'positioned' appropriately in an ISO-14258 table so as to characterise long, short and medium term processes (i.e. groupings of activities) of a particular ME and thereby can distinguish it from other MEs with different activity distributions and orderings. In this case Table 1 was constructed to illustrate a fleshing out of ISO activity classes found in a particular ME instance. The reader can deduce that for the ME characterised 'new product engineering' is realised by a set of tactical activities and therefore that the organisation is concerned with making products to stock or to order, rather than engineering products to meet specific order requirements.

\begin{tabular}{|c|c|c|c|}
\hline & "What" Activities & "How" Activities & "Do" Activities \\
\hline $\begin{array}{l}\text { Plan and build phase (e.g. } \\
\text { before sell/buy title } \\
\text { transfer) }\end{array}$ & $\begin{array}{l}\text { - Define ME strategy } \\
\text { - Develop ME goals } \\
\text { - Define ME product needs }\end{array}$ & $\begin{array}{l}\text { - Develop requirements } \\
\text { - Define concepts } \\
\text { - Design products } \\
\text { - Plan to produce products } \\
\text { - Plan to support products }\end{array}$ & $\begin{array}{l}\text { - Procure parts } \\
\text { - Produce products } \\
\text { - Test products } \\
\text { - Ship products }\end{array}$ \\
\hline $\begin{array}{l}\text { Use and operate phase (e.g. } \\
\text { after sell/buy title transfer) }\end{array}$ & $\begin{array}{l}\text { - Define uses of ME } \\
\text { products } \\
\text { - Define ME support needs }\end{array}$ & $\begin{array}{l}\text { - Define use requirements } \\
\text { - Define support requirements }\end{array}$ & $\begin{array}{l}\text { - Use products } \\
\text { - Support products }\end{array}$ \\
\hline $\begin{array}{l}\text { Dispose \& recycle phase } \\
\text { (e.g. after product is no } \\
\text { longer useful) }\end{array}$ & $\begin{array}{l}\text { - Define recycle/ dispose } \\
\text { needs of ME }\end{array}$ & $\begin{array}{l}\text { - Define recycle/ dispose } \\
\text { requirements }\end{array}$ & $\begin{array}{l}\text { - Recycle products } \\
\text { - Dispose products }\end{array}$ \\
\hline
\end{tabular}

Table 1: What, How, and Do enterprise activities in a specific ME (after BS ISO-14258)

\subsection{Andersen's Process Classes}

The ENAPS research program also classified BPs in MEs (Andersen 2000). This classification positions BP types into the two major classes illustrated by Figure 3; namely into 'prime' (customer related) BPs and 'secondary' BPs. A further segmentation groups common BP types with respect to their overall purpose.

\section{Primary Processes}

Andersen states that the 'prime' process class contains customer-related (or core) value-creating BPs of an enterprise. The process types attributed to this grouping are similar to process types contained within Pandya et al's (1997) 'generic operate' process class. However a difference between these two classifications lies within the detail; i.e. with which the purpose of each process type is described and the terminology used. 


\section{Prime Business Processes}

\section{Product Development Process}

* product research process

* product engineering \& design

* process engineering $\&$ design process

* co-engineering process

\section{Obtain Customer Commitment Process \\ * market development \\ * marketing \& sales \\ * tendering}

\section{Order Fulfilment Process}

* procurement/inbound logistics process

* production planning \& control

* manufacturing \& assembly

* distribution/outbound logistics

* order processing

\section{Customer Service Process}

* after sales service process

* product take back process

\section{Secondary (Business) Processes}

Support Process

* financial management process

* human resource management process

* information management process

* maintenance process

* control of health, environment and safety process

\section{Evolution Process}

* continuous business process improvement process

* product technology research process

* human resource development process

* supplier development process

* external relationships development process

* strategic planning process

Figure 3 Anderson's (2002) Process Classification

\section{Support Processes}

Process types belonging to Andersen's support process class are not considered to directly create value but are composed of activities that are necessary to support the operation of prime BPs. Hence Andersen's (2000) 'support processes' and Pandya et al's (1997) 'generic support' BPs have a similar overall purpose.

\section{Development Processes}

Andersen considered the purpose of processes types belonging to the evolution class to be to develop the value chain (comprising primary and support processes of a specific organisation) so that the organisation can attain a higher level of performance.

It follows that many similarities and some relatively minor differences exist between the Andersen and Pandya et al classifications. Regarding the differences, Pandya et al explicitly describe their management process class and state that this class includes processes responsible for strategy making, business planning and direct business. In contrast, Andersen suggests that 'strategic planning' is an integral part of a developmental (evolution) process class. However one might argue that this is merely a difference in interpretation and emphasis about common 'means' of realising change in MEs and whether those changes are considered mainly to be inspirational, developmental or evolutionary. Andersen explicitly emphasises the importance of evolving MEs in terms of their products, technology, strategies and business improvements. Thus ENAPS separates out key 
organisation improvement and business management improvement issues from the normal working of the organisation. On the other hand the ENAPS classification does not explicitly contrast the difference between the various timescales over which processes need to be managed and changed in complex organisations, nor does it explicitly concern itself with differentiation in the scope of concern of change processes. As stated previously however there is very strong correlation between the Pandya et al and Andersen classifications with respect to their generic operate and generic support process groupings.

At this point in the discussion it is important to bear in mind that any classification made about ME processes will be strongly influenced by the previous experiences of specific MEs possessed by classifying authors.

\subsection{Rose's 52 Business Processes}

Rose (2003) surveyed circa 200 UK SMEs with a view to classifying their BPs. His observations and survey results observed that at least 52 fairly distinctive process types were deployed by the businesses studied; where these SMEs operate in various industry sectors and product markets. Following ISO-9000 documentation recommendations about the nature of processes, Rose attributed the 52 enterprise processes to one or other of two process classes, namely:

\section{Generic Business Processes (GBPs)}

These are processes that are needed to manage and administer businesses.

2. Product Specific Processes (PSPs)

These are the processes that realise the development and production of products.

Rose's GBPs were also arranged into three groups, namely: 'Operational', 'Commercial' and 'Business Development' and observed that GBPs and PSPs need to interoperate to achieve enterprise goals over various timeframes.

\subsection{Multi-Process Orientation of Complex Manufacturing Organisations}

Pandya et al (1997), ISO-14258 (1998), Andersen (2003) and Rose (2003) all state that any given ME must deploy a finite set of human and technical resources to realise a network of dependent processes that itself needs to evolve over time. The same observation was made with reference to an earlier ME decomposition described by Salvendy (1992). Salvendy's decomposition describes the four process groupings illustrated by Figure 4. The overall purpose of Salvendy's 'manufacturing support' (MS) process group is to provide direct and 'standard' support for a so called 'production operation' (PO) process group used to directly generate products and services. Salvendy observed that typically this kind of support would ensure the provision of needed raw materials and 
equipment, and information and knowledge on how to use both. According to Koenig (1994), manufacturing support activities commonly realise "materials control", "quality control" and "manufacturing engineering" functions; where "manufacturing engineering" typically involves activities, such as "methods planning", "process control", "work measurement" and "maintenance", see Figure 5. Bearing in mind the observations of Salvendy (1992), Chatha (2004) suggested that ISO-14258 (1998) notions about activity classes and Koenig's description of manufacturing support processes can be used to flesh out Salvendy's process classification with respect to their strategic, tactical or operational emphases.
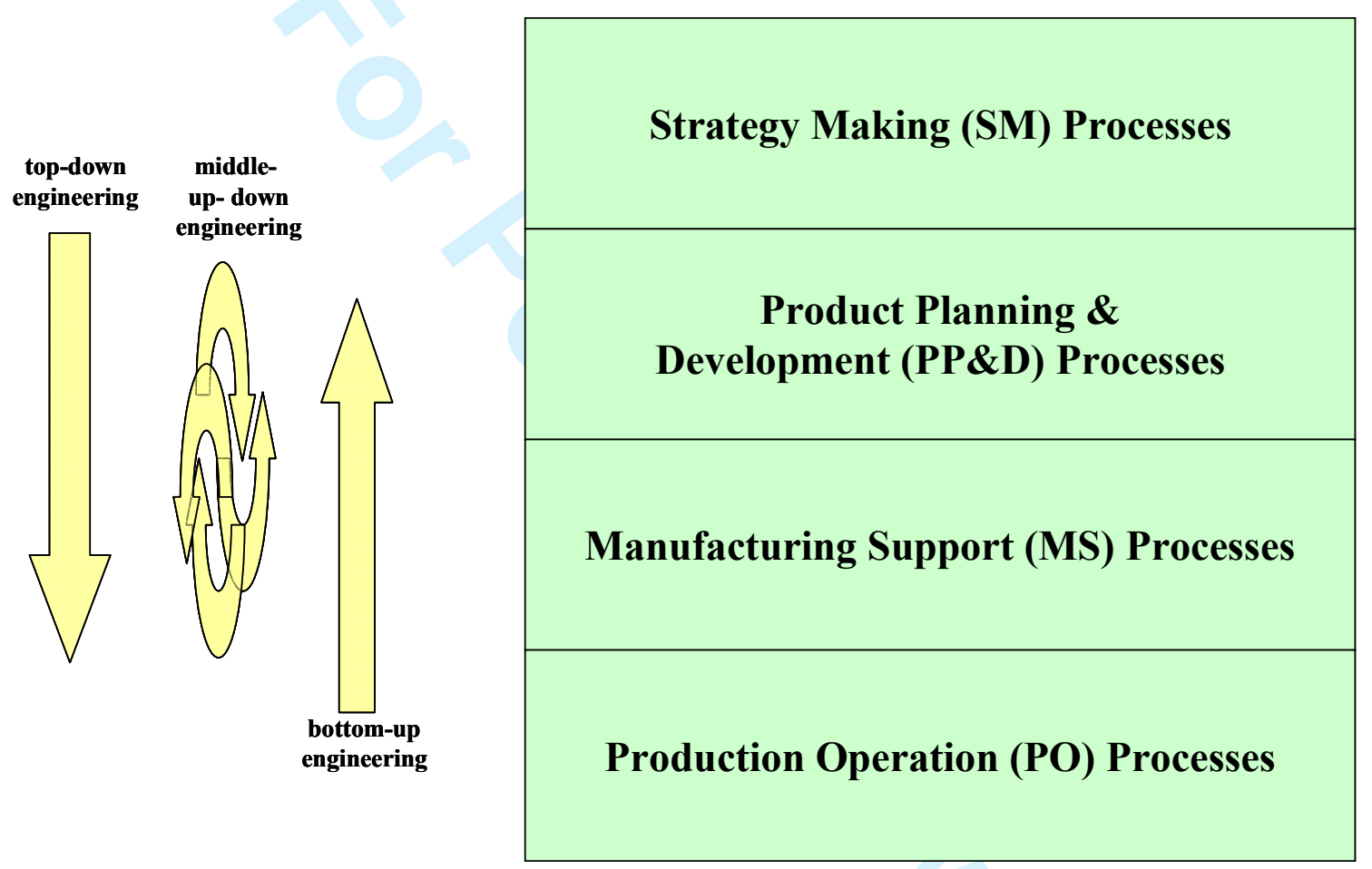

Figure 4 Process Set Common in MEs - after Salvendy (1992)

In the classification proposed by Chatha (2004) the prime purpose observed for processes within the strategic process class is to specify mid to long term objectives and plans of an enterprise. Strategies are created, and decisions taken about the type of business that should be created, developed or maintained and the goals that a business should achieve. The prime purpose of processes belonging to the tactical process class is to identify and achieve means of realising organisational goals defined by strategic processes, thereby enacting organisation design and engineering to ensure that the organisation has the capabilities, competencies, capacities and structures needed to realise strategic goals and objectives. Whereas processes within the operational process class typically constitute ordered sets of activities that realise mid to short term ME objectives (and thereby over time, longer term ME goals) by actually carrying out operations using capabilities, methods and techniques developed via tactical processes. 


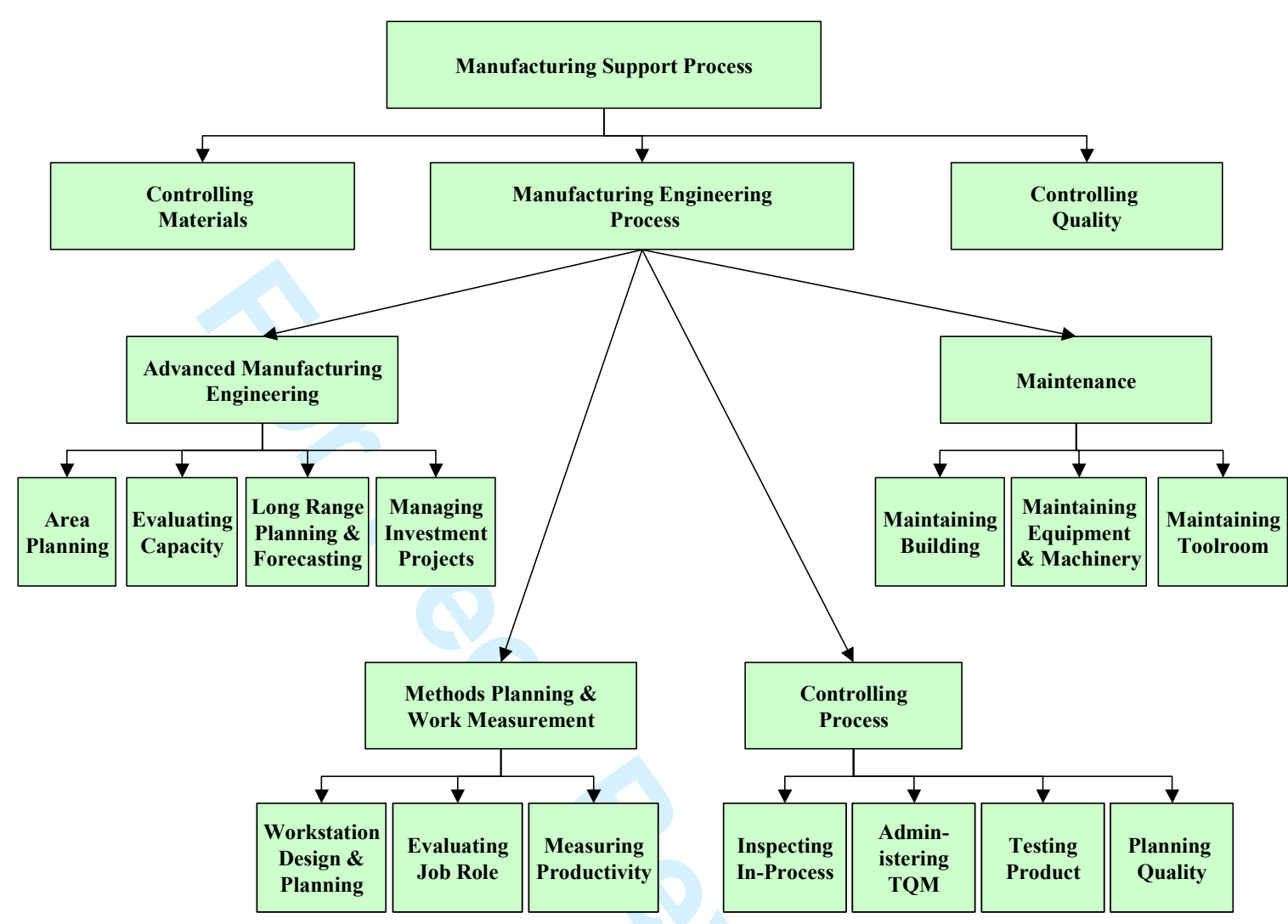

Figure 5 Manufacturing Support Process and its elemental sub-processes and activities (interpreted from Koenig, 1994)

Therefore all process classifications reviewed describe how complex organisations (such as Manufacturing Enterprises) can be conceptualised as a set of processes that function in an interrelated fashion changing during the organisation's lifetime. They also agree that specific descriptions of these three classes of process can describe the particular way in which any given ME achieves its particular purpose.

Chatha (2004) constructed a table of exemplary enterprise activities that form 'building blocks' of strategic, tactical and operational processes, see Table 2. The existence of strategic, tactical and operation processes emphasises the dependent multi-process nature of MEs, and that such a multiprocess network and interactions among activities belonging to different process classes need to change in response to strategic, tactical and operational instances and their embedded change requirements. 


\begin{tabular}{|c|c|c|c|}
\hline $\begin{array}{l}\text { Process } \\
\text { Class }\end{array}$ & $\begin{array}{l}\text { Activity } \\
\text { Class }\end{array}$ & \multicolumn{2}{|c|}{$\begin{array}{l}\text { Main Purpose of the Process/Activity within a Manufacturing } \\
\text { Organisation }\end{array}$} \\
\hline Strategic & What & \multirow{2}{*}{\multicolumn{2}{|c|}{ Define Business Objectives, Strategy, Business Plan }} \\
\hline \multirow[t]{4}{*}{ Processes } & activities & & \\
\hline & How & \multirow{2}{*}{\multicolumn{2}{|c|}{$\begin{array}{l}\text { Define Methods and Techniques to be used or developed: such as SWOT } \\
\text { Analysis, Gap Analysis, in order to create business strategy, plan, and } \\
\text { define business objectives }\end{array}$}} \\
\hline & activities & & \\
\hline & Do & \multicolumn{2}{|c|}{ Create Business Strategy, Plan, and Set Business Objectives } \\
\hline \multirow{4}{*}{$\begin{array}{l}\text { Tactical } \\
\text { Processes }\end{array}$} & What & \multirow{2}{*}{\multicolumn{2}{|c|}{$\begin{array}{l}\text { Define what needs to be done to Organisation Structures, Functions, and } \\
\text { Resources in order to implement business plans. Create tactical plans } \\
\text { such as area plan, quality plan, capability plan, maintenance plan etc. }\end{array}$}} \\
\hline & activities & & \\
\hline & $\begin{array}{l}\text { How } \\
\text { activities }\end{array}$ & \multicolumn{2}{|c|}{$\begin{array}{l}\text { Determine how to use or develop appropriate methods and techniques: } \\
\text { such as Capacity Analysis, Capability Analysis, Work Measurements, } \\
\text { Quality assurance etc. to inform, create and implement these plans. }\end{array}$} \\
\hline & $\begin{array}{l}\text { Do } \\
\text { activities }\end{array}$ & \multicolumn{2}{|c|}{$\begin{array}{l}\text { Practically implement these plans by getting information such as from } \\
\text { production operations }\end{array}$} \\
\hline \multirow[t]{3}{*}{$\begin{array}{l}\text { Operational } \\
\text { Processes }\end{array}$} & $\begin{array}{l}\text { What } \\
\text { activities }\end{array}$ & $\begin{array}{l}\text { Ensure tactics are followed and } \\
\text { implemented at the operation level }\end{array}$ & $\begin{array}{l}\text { Produce production plans and } \\
\text { ensure products are produced } \\
\text { properly }\end{array}$ \\
\hline & $\begin{array}{l}\text { How } \\
\text { activities }\end{array}$ & \multicolumn{2}{|c|}{$\begin{array}{l}\text { Use Resources (e.g. human, machines, materials), quality standards, } \\
\text { methods and techniques either developed at tactical level or specifically } \\
\text { used by people at the operation level, so as to achieve efficient resource } \\
\text { deployment, scheduling, knowledge capitalisation or liquidation, etc. }\end{array}$} \\
\hline & $\begin{array}{l}\text { Do } \\
\text { activities }\end{array}$ & \multicolumn{2}{|c|}{ Carry out operations needed to generate product, provide services, etc. } \\
\hline
\end{tabular}

Table 2: Common Processes and Activity Classes found in a Manufacturing Enterprise

\subsection{Common and Distinctive Features of the Process Classifications}

\section{Reviewed}

Evidently published process classes constitute a reflection and abstraction by their authors about common activity requirements observed in a number of MEs. It follows that each process classification will not be complete or definitive; in the sense that they must reflect limited understandings about a limited number of MEs, and because those understandings will have some bias and distinctiveness dependent on the competencies and previous experiences of classifying 
authors. However it also follows that by reflecting on combinations of published process classes resultant understandings should lead to a 'unified process classification' which reflects properties of a greater number of MEs and attenuates some of the effects of author bias. Hence the following paragraphs consider common and distinctive features of the process classes reviewed in the previous section, so as to lay groundwork needed to describe a 'unified process classification'.

It is important to point out however that comparisons drawn across published classifications must be open to interpretation by the observer; partly because the observer cannot be party to the exact meanings intended by all originating authors and partly because the terminology used to describe existing process classifications was intended to offer flexibility to users of the classifications. All published classifications reviewed in this paper use terminology which is designed to explicitly illuminate the prime purpose of included process types. Thereby chosen terminology enables users to position and group process types relative to other process types. However because in reality all MEs are unique, the chosen terminology could not convey all needed details of the characteristic properties of any specific ME process (or instances of it). Rather process classification terminology is implicitly designed to encourage its flexible use such as by enabling users to do one or more of the following: (1) conceive their own (personalised) mental reference model of processes they would expect (in theory) to find in most MEs; (2) compare their mental model with specific knowledge they have about specific case ME processes; (3) make better decisions and take better actions in regard to real case ME processes for which they have designated responsibility; and possibly (4) developed and publish improved process classifications.

Not withstanding their intended flexibility of use, the present authors believe that very significant similarity exists between the published process classifications reviewed in this paper; particularly with respect to the mental images they promote in the mind about the relative purposes of different ME process types. Generally the classifications use relatively minor differences in terminology to describe similar processes and similar properties. Also they may characterise the purpose of processes at different levels of abstraction. Commonality is also observed amongst all classifications reviewed in that there is (explicit or implicit) agreement that 'product and service generation' processes are needed by all MEs. Most classifications (explicitly or implicitly) describe the need for 'ME direction setting and related ME evolution' processes; although variation can be observed regarding the stated purpose and described level of abstraction of processes needed to renew and develop MEs. Also mention is made in all published classifications about the need for 'management processes'; but in most classifications management processes are considered to be distributed within members of other process classes. The Pandya et al (1997) and Andersen (2000) classes have commonality with each other but are distinctive from other classifications in that they 
separate out 'infrastructural support' process types. This aligns well with an observed trend in government, business and industry in recent decades to separately fund and manage infrastructure developments. More fundamentally it explicitly acknowledges that key decisions made, when designing and changing organisations that realise multiple products and services with a finite resource, relate to separating out (a) specific customer (or product) related value chains from (b) common support activities, needed to underpin the realisation of multiple products. This kind of process thinking can help to reinforce necessary separations of work items. By differentiating activities of an 'operate' or 'support' nature it is likely to prove possible to make better decisions as how best to resource, realise and manage (causally and temporally) dependent activity groupings. As a consequence improved ME competitiveness should result.

From the foregoing the present authors conclude that no major conflict exists between the underlying principles of all published process classifications reviewed in this paper. Indeed significant similarity was observed even though classifying authors came from both 'business schools' and 'systems engineering schools'. Apparently though there is some contradiction regarding specific partitioning and positioning of processes, and in the terms used to describe process elements. But detailed analysis reveals general agreement about (1) the need for a specific network of dependent processes in any given ME and (2) the essence of the process types that constitute (most if not all) ME process networks, albeit that actual process types, and dependencies between process types, will be specific in any given MEs. Because of 'essential similarity' between processes used in (probably most) MEs the present authors argue that collectively the existing process classifications reviewed provide a semantically rich, largely complementary set of reflections on $\mathrm{ME}$ processes. In principle the knowledge contained in these reflections can be usefully referenced when designing and changing manufacturing organisations.

There are however two distinctive underlying emphases within the ME process classifications reviewed. One such emphasis is focused on characterising the purpose of the classes (and types) of process needed so that MEs can function effectively on a day to day basis. The other emphasis concerns the need to renew, specify, manage, maintain, develop, change, etc, process networks and elements of those networks (that characterise the requirements of given MEs) through their lifetime. However close inspection of the original publications may be needed for readers to disaggregate these two emphases. Having referenced various published process classes in their ME design and change research work the present authors have observed that the Salvendy (1992) and ISO-14258 classifications are most definitively concerned about the latter emphasis than the former. The ISO and Salvendy classifications provide a simple, easy-to-use model (which can be populated with specific process types and/or process instants) but the level of abstraction used by the originating 
authors ignores (possibly deliberately hides) distinctions about the specific nature of processes. On the other hand the overall classification structure used by Salvendy and ISO emphasises the need to realise process change (large and small) in response to internal and external influences. A case can be made therefore for arguing that the Andersen (2000) classification is fairly comprehensive because it covers both emphases by describing the purpose and nature of many ME processes in detail and by explicitly separating out evolution processes. However the Andersen (2000) classification does not explicitly characterise dependencies between the two aspects, i.e. between 'process nature' and 'process lifetime' aspects of ME processes. On the other hand the Andersen classification does list common types of evolution process used to facilitate process development and engineering.

Table 3 Overview Characterisation of the Coverage of the Process Classifications Reviewed

\begin{tabular}{|l|c|cccc|}
\cline { 2 - 6 } \multicolumn{1}{c|}{} & $\begin{array}{c}\text { 'ME lifetime' } \\
\text { emphasis }\end{array}$ & \multicolumn{4}{c|}{ 'process nature' emphasis } \\
\cline { 2 - 6 } & $\begin{array}{c}\text { ME Lifecycle } \\
\text { Engineering } \\
\text { Processes }\end{array}$ & $\begin{array}{c}\text { Operational } \\
\text { Processes }\end{array}$ & $\begin{array}{c}\text { Infrastructural } \\
\text { Support } \\
\text { Processes }\end{array}$ & $\begin{array}{c}\text { Managerial } \\
\text { Processes }\end{array}$ & $\begin{array}{c}\text { Developmental } \\
\text { / Evolutionary } \\
\text { Processes }\end{array}$ \\
\hline $\begin{array}{l}\text { Pandya et al } \\
(1997)\end{array}$ & I & E & E & E & I \\
\hline $\begin{array}{l}\text { BSI/ISO-14258 } \\
(1998)\end{array}$ & E & I & I & I & E \\
\hline $\begin{array}{l}\text { Andersen } \\
\text { (ENAPS) }(2000\end{array}$ & I & E & E & I & E \\
\hline Rose (2003) & N & E & E & I & I \\
\hline Chatha (2004) & & & & I \\
\hline
\end{tabular}

Table 3 has been constructed to summarise observations made by the present authors about the scope of the ME process classifications reviewed in this paper, and their similar and distinctive features. Where there is explicit coverage of tabulated issues this is denoted ' $E$ ', implicit coverage is denoted ' $\mathrm{I}$ ' and negligible coverage is denoted ' $\mathrm{N}$ '. Also in this table 'developmental or evolutionary' process classes are separated out from 'managerial' processes, even though some published classifications couple these two forms of process into one. Explicit within the ISO-14258 (1998) and Chatha (2004) classifications is the notion that 'What', 'How' and 'Do' processes are needed to facilitate the lifecycle engineering of MEs and their specific process networks. Also explicitly mentioned by Chatha (2004) is the likelihood that strategic (direction setting) processes are concerned about ME evolution long term, tactical (ME and product engineering) processes typically have mid term ME developmental focus, operational processes commonly have long or mid term lifetimes but that specific instances of operational processes normally have relatively short 
term duration and often repeat regularly being triggered and completed following well defined beginning and end events. Both ISO and Chatha emphasise the need for process thinking, planning, management and control, and change over long, mid and short timeframes and with broad based through to narrow scopes of concern. However these classifications do not explicitly detail the purpose of all process classes needed within ME process networks, and only implicitly illustrate the impacts of lifecycle engineering processes on such a network.

\subsection{Proposed Unification of Previous Process Classifications}

\subsection{On the Need for a Unified Process Classification}

Over more than a decade the present authors and their undergraduate and postgraduate students have created and reused specific multi-perspective process-oriented models of a significant number of MEs (both large and small). To facilitate this modelling various enterprise modelling techniques, where founding approaches included CIMOSA (CIMOSA 1993), IDEF (IDEF User Group 1992), GRAI/GIM (Doumeingts 1990), ARIS (Scheer 1998), and PERA (Williams et al 1994). Because any ME is essentially a very complex system, that needs to interoperate with other complex systems (i.e. customer, supplier, stakeholder, competitor, governmental and environmental infrastructural systems) these modelling techniques were conceived so as to provide (I) a systematic method of decomposing complex systems into simpler sub-systems (that can be readily understood) and (II) modelling formalisms that enable identified sub-systems to be represented from those various points of view needed to facilitate the lifecycle engineering of MEs. Essentially these and other current generation public domain enterprise modelling techniques facilitate a two-staged modelling process routed in general 'systems engineering' practice where: firstly 'what needs to be done by the ME' is characterised by using the decomposition technique and modelling constructs provided to create a multi-perspective model of a specific ME process network; then secondly 'needed sets of interoperating resource systems' are determined by matching (available or possibly new) candidate configurations of resource systems to the ME requirements (defined by the multi-perspective process network model). Current generation enterprise modelling techniques are usually instrumented via computerised graphical modelling tools that can be deployed in conjunction with complementary analytical modelling, dynamic systems modelling, simulation modelling and workflow modelling techniques so as to design and change selected, relatively enduring and dynamic properties of MEs (Weston et al 2004). For example dynamic patterns of work (that arise from customer [requirements and order] change) can be mapped onto paired models of specific multi-perspective process networks and candidate resource systems (Ajaefobi et al 2006). For example simulation modelling can facilitate an ongoing matching (and evolution) of ME solutions (i.e. interoperating sets of resource systems loaded by alternative patterns of work) to well defined

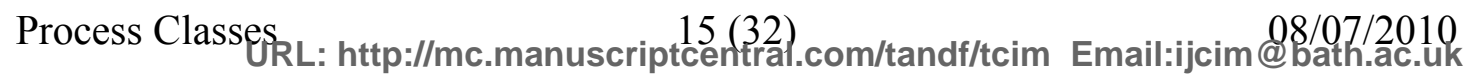


ME problems (described in terms of multiple instances of ME processes that are required to satisfy customer needs over short, mid and long timeframes). Whereas workflow modelling can be used in conjunction with enterprise modelling techniques to facilitate process enactment and model-driven interoperation and control of resource systems (Chatha et al 2003). Many publications report on the modelling work of the present authors and their colleagues that have created coherent enterprise, simulation and workflow models of specific ME process networks. This research has benefited significantly from referencing the ME process classifications reviewed in earlier sections of this paper.

When seeking to model the process network used by a new collaborating ME the present authors have commonly faced initial difficulties of understanding and communicating knowledge about (1) the threads of activity the ME under study needs to carry out (or may need to do in the future) to satisfy customer and stakeholder needs, (2) the (people, machine and IT) resource configurations needed by the company to realise those threads of activity, (3) how the dynamics of customer requirements impacts on the $\mathrm{ME}$ in terms of changing mixes of product realisation over time and thereby needed changes to configurations of resources, (4) what key problems (general or specific) are faced by the ME (or may need to be faced in the future) that constrain the lead-times, value generation, efficiencies, robustness and availabilities of its processes and resource systems or limit the fulfilment of possible future business models and manufacturing strategies. In such situations the process classifications reviewed in earlier sections of this paper have provided general reference models of processes which can readily be understood and used to share specific knowledge and understandings about how a specific ME under study currently operates, relative to 'standardised ME models' coded by published process classifications, and how it might operate more effectively in the future.

Typically exchange of knowledge between the present authors and relevant personnel within MEs under study has initially centred on understanding the nature of the operate processes used by the ME concerned. For example the 'end-to-end' flows of activity involved in multiple product realisation are discussed, as is their relationships with other 'end-to-end' processes ${ }^{1}$. This requires discussion about the frequency of repetition of processes and segments of processes, variances associated with their repetition, causal and temporal, dependency variances between threads of activity, material and information flow requirements, the need for resource systems with suitable capabilities, competencies and capacities, what values are generated by process segments as 'products' flow through the ME, and what resource costs are consumed as alternative products are

\footnotetext{
${ }^{1}$ Here the term 'end-to-end' is used to refer to processes (i.e. ordered sets of activities) with well defined start and end events that in most MEs need to repeat regularly, such as to respond on an ongoing basis to specific instances of product orders from customers.
}

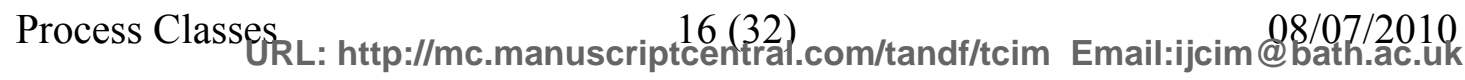


realised. All such topics can be discussed in the light of generally understood notions about process types such as 'obtain order', 'fulfil order', 'manage order fulfilment', 'design new product', 'introduce new product'. This kind of discussion naturally leads to an identification of what knowledge about processes currently exists in the company, and what related documents already exist within the company, that can be communicated to (the University) modellers. This naturally leads onto discussion and developed understandings about what infrastructural, tactical and strategic threads of activity occur (and over what timeframes and with what scopes of concern) within the ME and how (and on what timescales) these can be expected to impact on operate processes. This also naturally leads on to discussion about the ability of the ME to be workloaded by alternative product flows and product mixes. This in turn can generate common understandings about how the ME responds (or could in the future respond) to both predictable and unpredictable events and scenarios that arise because of changes in relevant environmental systems.

Subsequently having created multi-perspective computer models of the current (and possible future) process network, resource systems and dynamic patterns of work in the ME under study the published process classifications have continued to provide a 'common basis of understanding'. This has been used within modelled companies to help develop new understandings about causal and temporal impacts on the ME that would likely result from implementing recommendations for redesign and change uncovered by model-based analysis and related predictions about possible alternative ME futures.

Hence current process classifications have proven useful to the authors, their research colleagues and to collaborating companies. However those classifications have proven deficient with respect to explicitly promoting understandings about: common interdependencies between threads of activities in ME process networks; the iterative nature of common activities needed to change ME process networks; the types of process network change that can ensue; and common means by which process network change can best be realised. Therefore the authors have made proposals that unify aspects of previous process classifications into a 'unified process classification' which begins to address the deficiencies observed.

\subsection{A Unified Model of ME Processes}

Bearing in mind the foregoing, a unified reference model of ME processes was conceived by the present authors which brings together concepts embedded into earlier public domain process classifications. Figure 6 visually depicts the reference model proposed in the form of a network of (causally and temporally) related processes. This unified reference model cannot be claimed to be generic or complete, but it has usefully characterised common process types, and common organisational relationships between process types, found in many large and small manufacturing 
businesses with which the authors have conducted collaborative research. The proposed reference model conceptualises a separation between:

(1) operational processes that (normally on a repeating basis) realise and manage the generation of products and services for customers

(2) engineering processes that realise and manage the engineering of new products, processes, production methods and policies, and human and technical resource systems so that operational processes remain aligned to business and customer needs

(3) business-related processes that manage the business as a whole (i.e. maintain its financial viability by interfacing with investors, managing and allocating resources to business units, investment projects and infrastructural processes) and manage and lead the realisation of old and new strategies (so that the purpose, organisational objectives, organisational structures and business units satisfy customer and other environment needs long term)

(4) infrastructural support processes that provide common underpinning services to other ME processes.
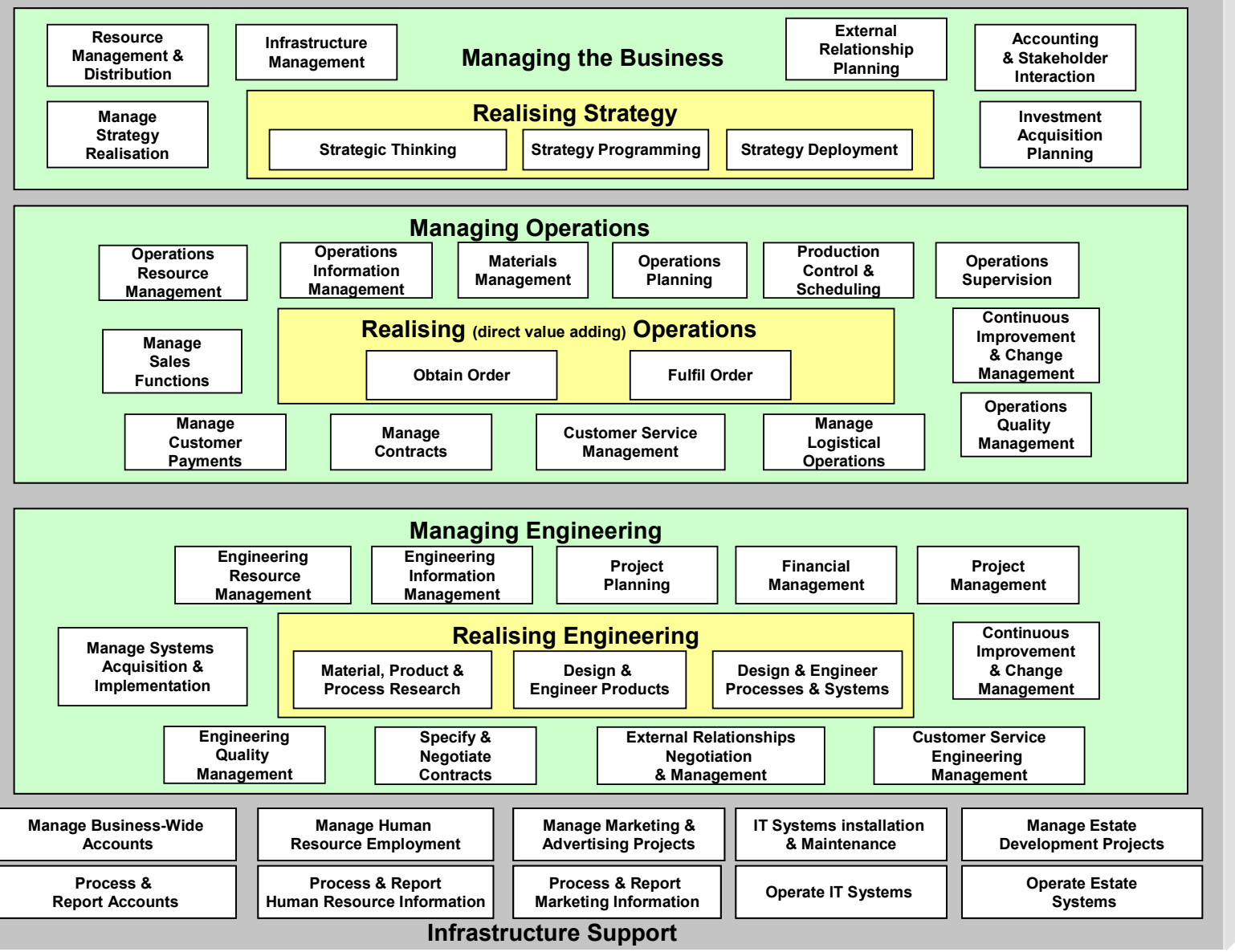

Figure 6 Unified Process Network Classification 
The unified reference model also conceptualises separations between managing and realising process types that belong to process classes (1) through (4).

In the case of the operate process class (1), there are two prime realisation process types, viz.: 'obtain order' and 'fulfil order', examples of which can be found in all MEs known to the authors. However the actual process logic of these process types will vary widely; dependent largely on the nature and quantities of products realised by a given ME, the number and geographical distribution of the customers involved and on the business and production policies the ME deploys. For example for an established product, sold and made in fairly large quantities, the 'obtain order' process logic might comprise relatively simple ordered sets of selling, order processing and customer invoicing and payment activities which need to be repeated many times (i.e. many 'obtain order' process instants will be needed over fairly short timeframes). However, if a new complex product (such as a production line or a football stadium) is required by a single customer the 'obtain order' process logic is likely to be very complex and may only be repeated once or a relatively small number of times. In such a case the term 'obtain contract' may be more representative of the process logic required (than the term 'obtain order') as typically contract bidding and negotiation, product conceptual design and specification, specification acceptance and product engineering activities may be needed, with responsibilities for these activities likely to traverse boundaries commonly established in MEs between process types (1) and (2). However for the sake of simplicity of representation, Figure 6 has been constructed bearing in mind that the 'obtain order' process type can be fairly simple or extremely complex. Whatever the detailed nature of 'obtain order' processes suitable human resources (such as salespersons and order processing clerical staff, who may or may not need to interoperate closely with technical and engineering staff), IT systems (e.g. order processing and accounting system and possibly estimating and engineering systems) and physical resources (such as cars, factory space and equipment) will be required to actually realise the process logic defined. Similarities and differences can also be observed between 'fulfil order' process types used in various MEs. Commonly activities such as materials and parts purchasing, parts production, parts assembly and finishing, parts and product inspection, and product packing and dispatching will need to be ordered temporarily in unique ways and appropriately and uniquely resourced by human and technical systems with the competencies, capabilities and capacities necessary to realise needed process logic within defined quality, delivery and cost constraints. Clearly significant differences in physical resource requirements can be observed when fulfilling orders for nuts and bolts, as opposed to computers, cars, production lines or a football stadium. But conceptual and logical similarities can be seen between needed sets of activities that transcend product types, and industry sectors.. 
The unified reference model provides example process types needed to manage operations in MEs on typically a day-to-day basis, but the intention is to be illustrative, rather than comprehensive. Like processes involved in realising operations, the importance (even existence) of each process type will be determined by the nature of products realised, the quantities realised, the customers and suppliers involved and ME policies adopted.

The reference model also includes illustrations of common process types belonging to class (2) processes needed to realise engineering and manage that realisation. Once again the specific application logic and resource systems utilised will be dependent on the nature of the products realised by the ME and the methods, techniques and tools adopted (which in turn may or may not be partly determined by industry sector norms). In cases where product engineering is essentially decoupled from product realisation (such as where an established product is made to stock, assembled to order or made to order) business opportunities may exist for a given ME to geographically distribute most of its process types belonging to class (1) to sites around the globe (e.g. to so called 'off-shore' locations), while siting process types under class (2) at a 'corporate' location.

Class (4) infrastructure process types, included into Figure 6 are also merely illustrative. In general large (possibly geographically distributed) organisations will need a comprehensive set of infrastructural support processes that help maintain uniformity and adherence across the ME, by realising support activities and services that are shared across business unit, departmental and tactical and operational organisational boundaries. Key examples include company wide: accounting and salary systems, managing human resources (e.g. centred on people hiring, retiring and firing and personnel appraisal and development), marketing, IT systems and information support and maintenance, and estates (building, security and cleaning) services.

Normally class (3) process types are realised mainly by senior executives and managers of MEs, who may use a variety of supporting systems. They have responsibility for direction setting and business planning and for running the business as a whole. They will need to secure sufficient financial resources by interfacing with stakeholders and will need to administer the distribution of income and profits (typically on an annual basis with reference to defined objectives, service levels and performance measures) to stakeholders, offshore companies, business units, departments and strategy realisation projects. Once again it is not the intention of the unified reference model to define all possible class (3) process types found in MEs. But the model does emphasise the importance of strategy realisation. Section 5 of this paper discusses further the nature of 'realise strategy' process types. This focus of attention has been selected because previous process classifications have paid relatively little explicit attention to this topic, even though it is of vital 
importance to businesses that operate within dynamic and unpredictable environments. First, however, it is necessary to consider the nature of ME change projects, hence the general discussion included into section 4.3.

The unified reference model proposed and visually represented by Figure 6, helps view any given process network from short (operational), mid (engineering/tactical) and long (strategic) term perspectives. Those perspectives typically align well with responsibility assignments to organisational groupings found in MEs, particularly in mid sized and large MEs. However in reality these separations may be somewhat artificial, particularly in SMEs; and generally there will be common memberships of personnel within people systems used to realise operational, engineering and business-related processes. None the less the generalised process decomposition embedded into the reference model helps clarify conceptual thinking about MEs, and by so doing help cut through the complexity and dynamism inherent within contemporary organisations.

\subsection{On the Nature of ME Process Network Change and the Importance of Process Dependencies}

Figure 7 conceptualises an iterative chain of common activities that give rise to large and small scale change to any process (or the network of processes) used by a specific ME. The overall purposes of this activity chain is: to renew the composition (of resource systems) and structures (that 'bind' resource systems) of the ME, so that the ME continues to fit its purpose; maintain and manage coherence in the ME, whilst facilitating innovation; and to ensure that day-to-day ME operations lead to cost effective and timely product and service realisation (for customers) and value generation (for internal and external stakeholders). Obviously different MEs will be subject to alternative market, competitor and other environmental influences, which may vary predictably or unpredictably over differing timescales. It follows that to evolve any given ME process network, specific instances of the generic change activities listed in Figure 7 will need to be realised; having normally been appropriately distributed into 'realising strategy', 'managing the business', 'managing engineering', 'managing operations' and 'infrastructure support' process types. Table 4 lists specific examples of these common activities involved in realising process network change. 


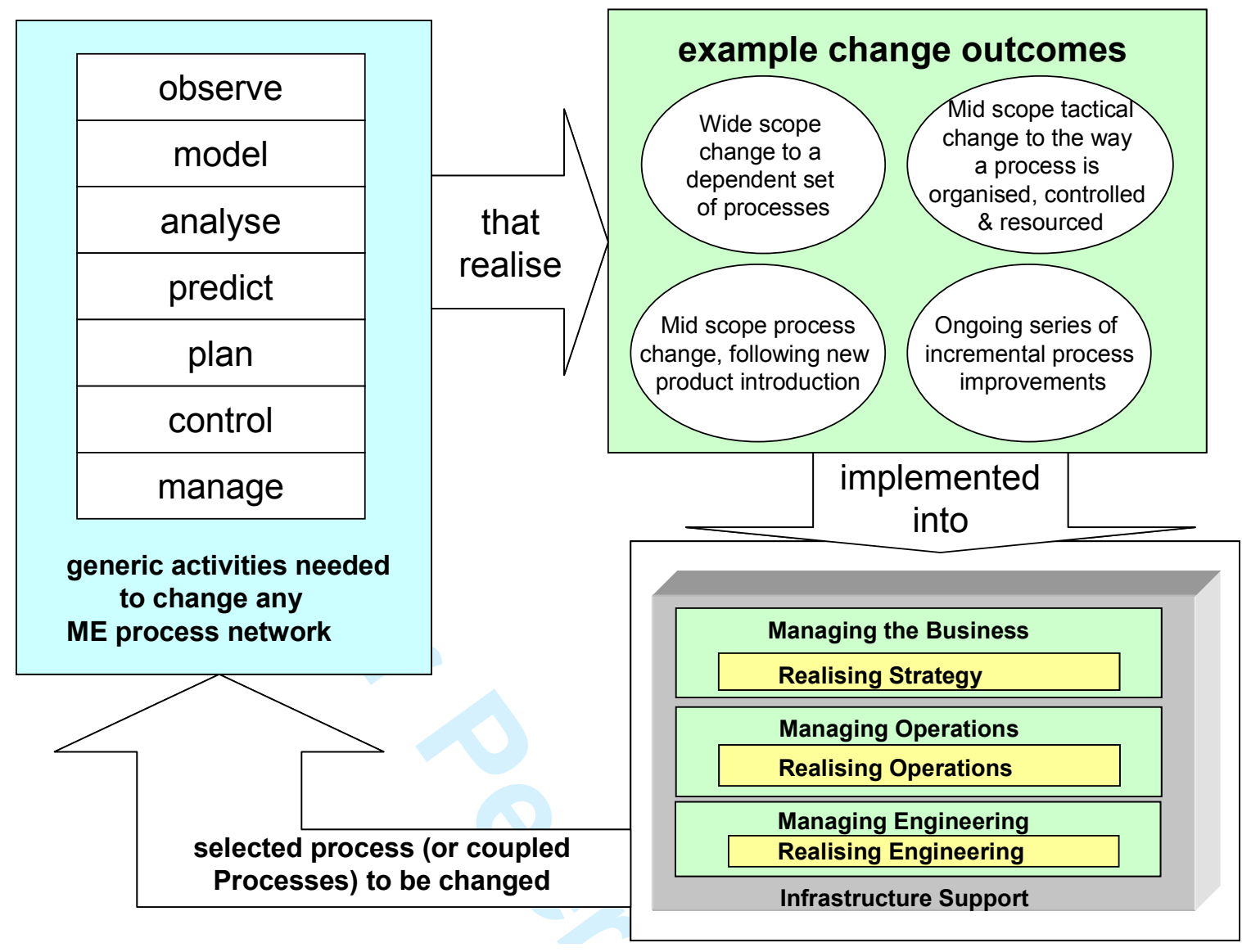

Figure 7 Generic Activities needed to change process networks

\begin{tabular}{l|l}
\hline Observe & $\begin{array}{l}\text { Observe market requirements, competitor strengths and stakeholder needs. } \\
\text { Observe political, economic, social and technical conditions. } \\
\text { Observe business patterns and trends. } \\
\text { Measure performance of current ME process network. }\end{array}$ \\
\hline Model & $\begin{array}{l}\text { Markets, patterns and structures. } \\
\text { Alternative ME process networks and operating policies. } \\
\text { Partnership structures \& capability distributions. } \\
\text { Effects of uncertainty and risk. }\end{array}$ \\
\hline Analyse & $\begin{array}{l}\text { Strategies for renewal. } \\
\text { Strategies and tactics for innovation. }\end{array}$ \\
& Impact of alternative ME process networks and operating policies. \\
\hline Predict & $\begin{array}{l}\text { Importance of alternative change projects. } \\
\text { Required order, component, stock and asset levels. } \\
\text { Human resource requirements. }\end{array}$ \\
\hline Plan & $\begin{array}{l}\text { The formation of new partnerships. } \\
\text { New system and capital equipment projects. }\end{array}$ \\
& $\begin{array}{l}\text { New product introduction scenarios. } \\
\text { Process and quality improvement programmes. } \\
\text { Knowledge capitalisation activities. }\end{array}$ \\
& $\begin{array}{l}\text { Resource allocation and distribution. } \\
\text { Interactions between processes of the ME process network. } \\
\text { New system and capital equipment programmes }\end{array}$ \\
\hline Control & Financial budgets. \\
& Activity, product and information flows. \\
& Human resource recruitment and training \\
\hline
\end{tabular}

Table 4. Common Examples of the Generic Change Activities 
In some MEs close causal and temporal couplings may need to be maintained between different process types, both within and across boundaries of process classes. For example in so called 'Engineer To Order' (ETO) businesses, instances of 'obtain order (or obtain contract)', 'design and engineer product', 'design and engineer processes and systems' and 'fulfil order' process types will need to operate synchronously, with overall synchronisation directed and managed in a timely and effective manner by instances of process types belonging to 'managing the business', 'managing engineering', managing operations' and 'infrastructure support' classes. It follows that any changes made to these process types in an ETO ME must be cognisant of their causal and temporal dependencies. In 'Make To Stock' (MTS) MEs, instances of 'design and engineer product', 'design and engineer processes and systems', 'fulfil order' and 'obtain order' processes will be executed essentially independently and asynchronously; and as a consequence in MTS MEs specifying and realising change may be significantly easier than in ETO MEs. Commonly however, in a single large ME multiple product realising strategies (like ETO, Make to Order (MTO), Assemble to Order (ATO), Configure to Order (CTO), Ship to Order (STO) and MTS) may be deployed with respect to different ME products (or even the same product); and this will further complicate characteristic (causal and temporal) dependencies between process types. It follows that: cost effective and timely realisation of ME process instants and short, medium and long term management of dependencies between these instants is important in many MEs. Here it is emphasised that it is not only the specific nature of process instants that leads to competitive differentiation between MEs, but also specifics of the way in which dependencies between process instants are managed and how needed changes are realised.

Any given set of processes, process instants and dependencies between process instants will need to be continuously scrutinised and as needed they should be changed to ensure that they remain fit for purpose. It follows that irrespective of the scope, frequency and time frames over which those changes need to occur it is evident that ME processes must be 'observed', 'modelled' and 'analysed', and that their possible futures need to be 'predicted' and 'planned', so that suitable future process networks (which have needed changes embedded into them) can be 'implemented', 'resourced' (by suitable human and technical resource systems), 'controlled' and 'managed'. However the way in which, the scope with which and the timescale over which these common activities need to realise process network change will be determined by specifics of the change (development or evolutionary) processes deployed by a given ME. If the change to a process or process network is small in scope and scale it may be managed and supported wholly within an ME. However, if the scope and scale of change extends beyond the boundaries of the ME and/or change requirements are beyond the available competencies of the ME, outside organisations will need to 
be involved in change projects; where those organisations may be specialists in change management.

\subsection{Strategy Realisation Processes and their Importance to MEs}

\subsection{Strategy Realisation in MEs}

Mintzberg (1994) observed that strategy realisation (a) involves three distinct phases of activity, namely 'strategic thinking', 'strategy programming' and 'strategy deployment' and (b) requires strategists to move iteratively between these phases. Various other authors agree that iteration between strategy realisation project phases is necessary to realise effective strategies (Ansoff 1965, Courtney et al 1997, Graetz 2002, and Freedman 2003) but they do not explicitly separate and define the project phases involved, rather typically they refer to 'phases of strategic planning'. With the purpose in mind of creating a clear and explicit reference model of ME processes, the present authors have adopted Mintzberg's definition of phases of strategy realisation projects.

As they think about alternative ME futures, and alternative ways of realising new organisational configurations that can give rise to preferred futures, it is probable that few personnel in small and mid sized MEs consider themselves to be deploying a well defined strategy realisation process (Ansoff and McDonnell 1990 and Lorange and Vancil 1977). On the other hand some large corporations invest significant resources to improve upon the processes used by their personnel to realise new and improved strategies (Huff 1994 and Heracleous 1998). Advising MEs about strategy realisation concepts, methods and tools constitutes a core operational business process of many (large and small) technical and business consultancy organisations (Kaplan and Norton 200 and Mintzberg et al 1998 and Hammer and Champy 1993).

In our experience, (a) responsibility for managing strategy realisation processes invariably resides within business-related organisational groups (and their class (3) processes), and (b) strategy realisation processes are seldom explicitly recognised and well understood by most ME personnel. Supporting evidence for these observations can be found in the literature (Harrison 1995 and Hamel 1996). Whereas responsibility for realising strategy is generally shared and should explicitly be distributed amongst business-related, engineering, operational and infrastructural groupings; albeit that strategic thinking is normally centred on business personnel, strategy programming typically concerns business, engineering and infrastructural personnel and strategy deployment commonly involves all organisational groups (Seaker and Wallace 1996, Magretta 2002, O’Brien 2003 and Hamel 1996).

The present authors have observed distinctly different strategy realisation practice in MEs. Firstly different strategy realisation techniques are deployed, examples of which are categorised by Figure 
8, under the headings 'SR concepts', 'SR methods' and 'SR tools'. Secondly normally MEs and their consultant advisors will only deploy a small subset of the techniques categorised. Thirdly any set of techniques chosen will usually be used in a piecemeal, rather than an integrated fashion. Bearing in mind that any significant change in strategy will likely require multiple strategy implementation projects to be financed and resourced by suitable personnel over significant timeframes, then logically one might expect that a piecemeal and somewhat ad hoc use of SR techniques must reduce opportunities to reuse project information and knowledge and must impact negatively on the effectiveness and timeliness of adopted strategies (Shekkerman 2003).

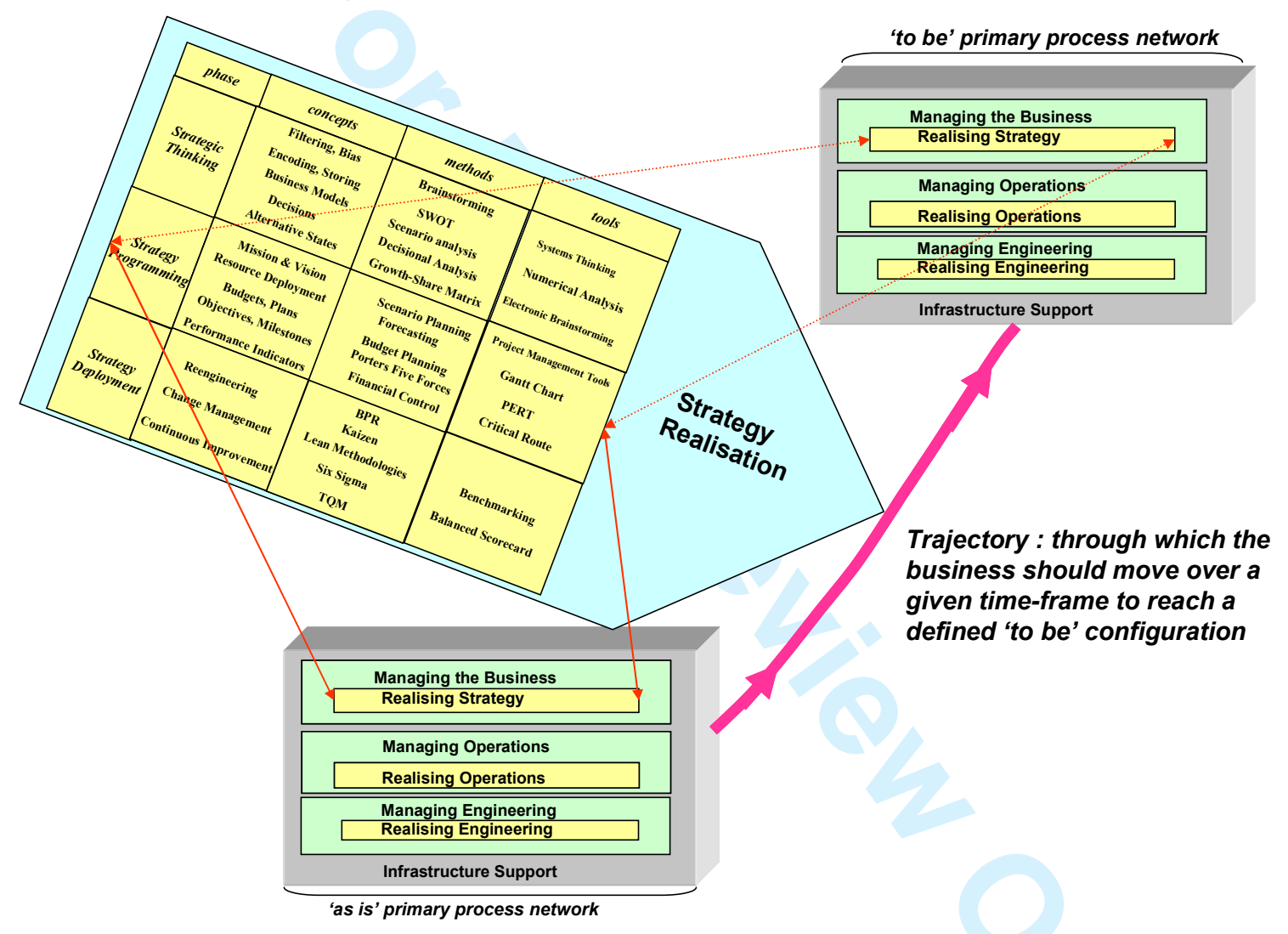

Figure 8 Purpose of Strategy Realisation Processes

Denton (2003) observed (1) that few UK SMEs engage systematically in strategy realisation despite their being relatively small (and hence one might presume relatively dynamic) and (2) that currently the average lifetime of UK SMEs is only circa 4 years (Department of Trade and Industry 2004). It may well be the case that (1) is a major causal factor of (2).

\subsection{On the Need to Systemise and Instrument Strategy Realisation}


The unified reference model of processes depicted by Figure 6, makes explicit the importance of strategic thinking, strategy programming and strategy deployment in ensuring that any ME is competitively aligned to its relevant customer, stakeholder and environmental systems. To develop this thread of thinking, Figure 7 categorises common techniques that MEs can deploy to realise strategies. Over more than two decades the present authors and their research colleagues have investigated and applied a number of modelling techniques and tools that naturally lend decision making support to personnel involved in different aspects of strategy realisation. Within those modelling studies we have observed that three common types of modelling will likely prove beneficial, namely 'opportunity modelling', 'requirements modelling' and 'system solution modelling'.

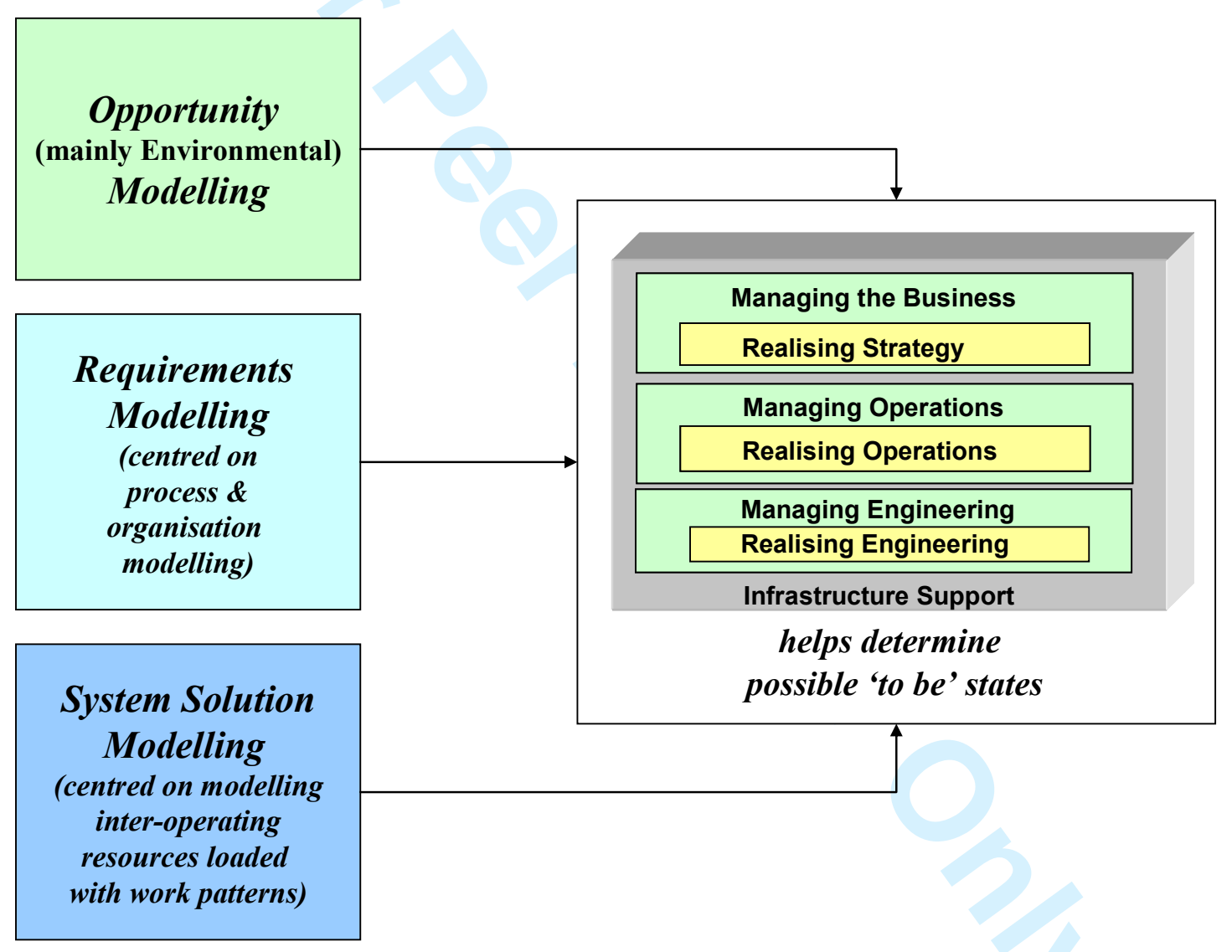

Figure 9 'Types of Modelling' - observed as being needed to support SR

As illustrated by Figure 9 these different modelling perspectives offer complementary ways of viewing ME processes, and their associated resource systems and workflows. In various industrial case studies ME models have been captured, validated and computer executed to predict and analyse possible 'to be' ME behaviours. This has helped collaborating companies to make investment decisions and to plan and implement large and small scale ME change. 
Table 5 has been constructed to summarise example uses of modelling technologies (that coupled to the use of reference models of processes, resource systems and work patterns) have helped instrument various methodologies defined by business schools. Although significant outstanding research and development work remains, already the generic and semi-generic understandings incorporated into the unified reference model of ME processes introduced by this paper have usefully informed (and thereby improved upon) best practice in large and small MEs.

\begin{tabular}{|c|c|c|c|c|c|}
\hline Purpose of Modelling & Nature of Modelling & Focus of Modelling & $\begin{array}{l}\text { Example Threads } \\
\text { of Modelling }\end{array}$ & $\begin{array}{l}\text { Useful 'Business } \\
\text { School' Concepts }\end{array}$ & $\begin{array}{l}\text { Candidate Modelling } \\
\text { Technologies }\end{array}$ \\
\hline $\begin{array}{c}\text { Opportunity } \\
\text { Modelling }\end{array}$ & $\begin{array}{c}\text { abstract structural \& } \\
\text { behavioural modelling, } \\
\text { of wide scope with a } \\
\text { medium to long-term } \\
\text { focus }\end{array}$ & $\begin{array}{l}\text { modelling causality } \\
\text { between the ME } \\
\text { \& its environments } \\
\text { to identify strategic } \\
\text { opportunities }\end{array}$ & $\begin{array}{l}\text { * Analyse market structure, } \\
\text { requirements \& opportunities } \\
\text { * Analyse product portfolio } \\
\text { opportunities } \\
\text { * Analyse competitor } \\
\text { strengths \& weaknesses } \\
\text { * Conduct internal capability } \\
\text { analysis } \\
\text { * Identify candidate strategic } \\
\text { intents }\end{array}$ & $\begin{array}{l}\text { * Scenario Planning } \\
\text { * Game Theory } \\
\text { * Porters Forces } \\
\text { * Organisational Structure } \\
\text { (Mitzberg \& Walters) } \\
\text { * Supply Chain Analysis } \\
\text { * Process Classifications } \\
\text { * Competitor Analysis } \\
\end{array}$ & $\begin{array}{l}* \text { Dynamic systems } \\
\text { modelling } \\
* \text { Causal loop modelling } \\
* \text { Dependency \& } \\
\text { constraints modelling } \\
* \text { Simulation based on } \\
\text { numerical integration }\end{array}$ \\
\hline $\begin{array}{l}\text { Requirements } \\
\text { Modelling }\end{array}$ & $\begin{array}{l}\text { primarily mid-level } \\
\text { abstractions of } \\
\text { structural aspects, } \\
\text { of medium to wide } \\
\text { scope with a medium } \\
\text { to long-term focus }\end{array}$ & $\begin{array}{l}\text { modelling of needed } \\
\text { process oriented } \\
\text { organisational forms } \\
\text { that the ME can } \\
\text { use to compete } \\
\text { for identified } \\
\text { opportunities }\end{array}$ & $\begin{array}{l}\text { * Analyse business process } \\
\text { networks relative to candidate } \\
\text { strategic intents } \\
\text { * Analyse supply chain } \\
\text { alternatives } \\
\text { * Analyse work organisation } \\
\text { alternatives under financial } \\
\text { \&resource constraints } \\
\text { * Analyse \& short list viable } \\
\text { production strategies } \\
\text { * Identify candidate business } \\
\text { models }\end{array}$ & $\begin{array}{l}\text { * Porters Forces } \\
\text { * Organisational Structure } \\
\text { * Process Classifications } \\
\text { * Benchmarking } \\
\text { * Process configurations } \\
\text { (MTS-MTO-ETO etc) } \\
\text { * Product Structure } \\
\text { * VAT Plants } \\
\text { * Postponement } \\
\text { * Lean/JIT/Agile }\end{array}$ & $\begin{array}{l}\text { * Enterprise \& process } \\
\text { modelling } \\
* \text { Various types of } \\
\text { simulation modelling } \\
* \text { Value stream analysis } \\
* \text { Cost modelling } \\
* \text { Decision network } \\
\text { modelling }\end{array}$ \\
\hline $\begin{array}{l}\text { System Solutions } \\
\text { Modelling }\end{array}$ & $\begin{array}{l}\text { primarily mid to low } \\
\text { level abstractions of } \\
\text { structural \& } \\
\text { behavioural aspects, } \\
\text { of narrow to medium } \\
\text { scope with a short } \\
\text { to medium-term focus }\end{array}$ & $\begin{array}{l}\text { modelling to inform } \\
\text { the resourcing of } \\
\text { process-oriented } \\
\text { roles with candidate } \\
\text { human \& technical } \\
\text { systems \& analysing } \\
\& \text { predicting their } \\
\text { behaviours when } \\
\text { subject to work } \\
\text { pattern dynamics }\end{array}$ & $\begin{array}{l}\text { * Identify process oriented roles } \\
\text { amongst viable Business Process } \\
\text { networks } \\
\text { * Match viable candidate human } \\
\text { \& technical resource systems to } \\
\text { identified roles } \\
\text { * Analyse competitor } \\
\text { strengths \& weaknesses } \\
\text { * Exercise resourced roles } \\
\text { with historical and predicted } \\
\text { work patterns } \\
\text { * Select suitable work structures via } \\
\text { dynamic analysis of short listed } \\
\text { business \& production strategies }\end{array}$ & $\begin{array}{l}\text { * Process classifications } \\
\text { * Postponement } \\
\text { * Lean } \\
\text { * JIT- Kanban } \\
\text { * CONWIP } \\
\text { * Agile } \\
\text { * Competency models } \\
\text { * Team working theory } \\
\text { * Scheduling techniques } \\
\text { * Flexibility theory }\end{array}$ & $\begin{array}{l}* \text { Enterprise \& process } \\
\text { modelling } \\
* \text { Discrete event simulation } \\
* \text { Value stream analysis } \\
* \text { Cost modelling } \\
* \text { Role modelling } \\
\text { * Resource capability } \\
\text { modelling } \\
* \text { Work pattern modelling } \\
* \text { Exception modelling }\end{array}$ \\
\hline
\end{tabular}

Table 5 Candidate Modelling Technologies- that support key aspects of strategy realisation

\subsection{Discussion and Conclusions}

The present authors posit that, relative to any previous published process classification, the unified reference model of ME processes introduced by this paper:

(1) more comprehensively characterises the generalised process network commonly deployed by MEs (and partnerships of MEs) to ensure that: day to day ME operations lead to value generation, through cost effective and timely product and service realisation; coherent interworking of ME systems of (human and technical) resources is specified and 
maintained, whilst enabling innovation and change; and the purpose and composition of the ME continues to be renewed, so that the ME fits its purposes during its lifetime;

(2) encodes a natural (and commonly observed) decomposition of general ME processing requirements (i.e. what MEs need to do) which can help to characterise general causal and temporal dependencies between processing elements. This decomposition can be mapped onto generalised models of ME types (such as ETO, MTO, ATO and MTS MEs) and onto generalised roles and responsibilities for people and machine systems. When realising ME change on any significant scale it will be imperative to operationalise and develop collective understandings about a specific ME process network by persons responsible for network segments, and the whole network, short, medium and long term.

(3) can more readily be deployed by technical, consultant and academic modellers to elicit, interpret, analyse and communicate information about a specific ME. Section 4.1 describes how the reference model has enabled enterprise models, simulation models and workflow models of collaborator businesses to be created and communicated with reduced effort.

The previous classifications of processes reviewed by this paper are essentially consistent with the new reference model of ME processes proposed. Therefore collectively those publications describe common characteristics, process types and process classes that constitute much of the new reference model. However the present authors believe that key interdependencies exist between process types and classes in any given ME which have a significant influence on achievable characteristic behaviours. Hence following subsections of this paper illustrate the nature of typical process dependencies in different types of ME.

Table 6 Process thinking \& process modelling application areas, that can be 'informed' by the unified reference model of processes

\begin{tabular}{|c|c|c|}
\hline $\begin{array}{l}\text { Business Process } \\
\text { Engineering }\end{array}$ & $\begin{array}{l}\text { Value Stream } \\
\text { Analysis }\end{array}$ & $\begin{array}{c}\text { Knowledge Management \& } \\
\text { Capitalisation }\end{array}$ \\
\hline Business Process Change & $\begin{array}{l}\text { Process Simulation \& Performance } \\
\text { Optimisation }\end{array}$ & $\begin{array}{l}\text { Work Organisation \& } \\
\text { Factory Layout Design }\end{array}$ \\
\hline Continuous Process Improvement & Lead-time Reduction & Factory Animation \\
\hline $\begin{array}{l}\text { Software System } \\
\text { Selection }\end{array}$ & Process \& Activity Based Costing & Project Management \\
\hline $\begin{array}{l}\text { Customising } \\
\text { Standard Software }\end{array}$ & $\begin{array}{l}\text { Human Resource } \\
\text { Planning }\end{array}$ & Certification \\
\hline $\begin{array}{l}\text { Workflow Specification } \\
\& \text { Control }\end{array}$ & Team System Design & Benchmarking \\
\hline
\end{tabular}


The authors believe that the unified reference model of common ME processes introduced by this paper has potential to support most (if not all) types of organisation design and change project centred on process thinking. Table 6 classifies some major project types for which support can be given.

\section{References}

Ajaefobi, J O, Weston, R H and Chatha, K A, "Predicting the performance of candidate human systems within specific work contexts". Accepted IJCIM Jan 2006.

Al Mashari, M., and Zairi, M., 1999, "BPR Implementation process: an analysis of key success and failure factors", Business Process Management Journal, Vol.,5, No.1, pp. 87-112.

Andersen, B. and Fagerhaug, T., 2000, "Performance Measurement of Logistics Processes", Proc. ICT in Logistics \& Production Management, IFIP WG5.7, June, Tronso, Norway.

Ansoff, I.H., 1965, "Corporate strategy: an analytical approach to business policy for growth and expansion”, Mc Graw Hill, USA, ISBN: 0140209328

Ansoff, I.H., and McDonnell, E.J., 1990, “Implanting Strategic Management”; Prentice Hall, UK, ISBN: 0134519159

Brahm, C. and Kleiner, B., 1996, “Advantages and disadvantages of group decision approaches”, Team Performance Management: An International Journal, Vol. 2, no.1, pp. 30 - 35.

BS ISO-14258. (1998). "Industrial Automation Systems - Concepts and Rules for Enterprise Models", British Standards Institute, Chiswick, London.

Chatha, K.A., Weston, R.H., and Monfared, R.P., 2003, “An Approach to modelling dependencies linking engineering processes", Proc. of Inst. of Mech. Eng., Part B: Journal of Engineering Manufacture, Vol. 217, pp669-687.

Chatha, K.A., Ajaefobi, J.O. and Weston, R.H., 2006, "Enriched Multi-Process Modelling in support of the life cycle engineering of business processes”. Accepted by IJPR Dec 2005.

Chatha, K.A., 2004. "Multi-Process Modelling Approach to Complex Organisation Design”. PhD Thesis Wolfson School of Mech. and Manuf. Eng., Loughborough, University.

CIMOSA 1993 ESPRIT Consortium., “AMICE: Open System Architecture for CIM”, Second revised and expanded edition, Springer-Verlag, Berlin.

Corner, P.D., Kinicki, A.J., Keats, B.W., 1994, "Integrating Organisational and Individual Information Processing Perspectives on Choice”; Organisation Science, vol. 5, no. 3, pp. 294 - 308. 
Courtney H., Kirkpatrick, J., and Viguere, P., 1997 “Strategy under uncertainty”, Harvard Business Review, vol. 75 , no. 6 , pp. $66-79$.

Craig, C.S., and Douglas, S.P., 1997, "Responding to the Challenges of Global Markets: Change, Complexity, Competition and Conscience”, IEEE Engineering Management Review, pp4-14.

Denton, P, 2003. "Business strategy driven IT systems for engineer-to-order and make-to-order manufacturing enterprises". $\mathrm{PhD}$ Thesis, Wolfson School of Mech. and Manuf. Eng., Loughborough University.

Department of Trade and Industry 2004, Department of Trade and Industry; Statistical Press Release: Business start-up and closures: VAT registrations and de-registrations in 2003; (available online http://www.sbs.gov.uk/SBS_Gov_files/researchandstats/news171.pdf)

Doumeingts, G., 1990, “Modelling Techniques for CIM”, Proc. ESPRIT CIM Workshop 'Computer Integrated Manufacturing Open Systems Architecture, Brussels, March. XIII/135/90/EN.

Drucker, P.F. 1990. “The Emerging Theory in Manufacturing”. Harvard Business Review, 3, pp94102.

ESPIRIT-CIMOSA Standards, 1993, “CIMOSA: Open System Architecture for CIM”, SpringerVerlag.

Freedman, M., 2003, “The Genius is in the implementation”, Journal of Business Strategy, vol. 24, no. 2 , pp. $26-31$.

Graetz, F., 2002, "Strategic thinking versus strategic planning: towards understanding the complementarities", Management Decision, vol. 40, no. 5, pp. 456 - 462.

Hamel, G., 1996, “Strategy as revolution”, Harvard Business Review, vol. 74, no. 4 , pp. 69 - 82.

Hammer, Michael; Champy, James, 1993; Reengineering The Corporation: A Manifesto For The Business Revolution, Brealy Publishing Ltd, 2001, United Kingdom.

Harrison, F.E., 1995, "Strategic planning maturities", Management Decision, vol. 33, no. 2, pp. 48 $-55$.

Heracleous, L., 1998, “Strategic Thinking or Strategic Planning?”; Long Range Planning, vol. 31, no. 3 , pp. $481-487$.

Huff, A. 1994 (Editor), “Mapping strategic thought”; Wiley, UK, ISBN: 0471926329

ICAM, 1995, “IDEF3 Process Description Capture Method Report”, Knowledge Based Systems Incorporation, Texas, [http://www.idef.com/idef3.html]. 
IDEF User Group, 1992, “The IDEF Framework, IDEF-UG-0001”, version 1.5 (IDEF User Group, Kettering, OH, USA).

Imai, M. 1986. “Kaizen: The Key to Japan’s Competitive Success”. New York: Random House.

Kaplan, R.S., and Norton, D.P., 2000, "Having trouble with your strategy? Then map it", Harvard Business Review, vol. 78, no. 5, pp. $167-176$.

Koenig, D.T., 1994, “Manufacturing Engineering: Principles for Optimisation”, Taylor and Francis, USA, ISBN: 1-56032-301-9.

Lorange, P. and Vancil, R. F. (editors), 1977, "Strategic planning systems", Prentice-Hall, Great Britain, ISBN: 0138510067

Magretta, J., 2002, “Why Business Models Matter”, Harvard Business Review, vol. 80, no. 5, pp. $86-92$.

Mertins, K., and Jochem, R., 1998, "Integrated Enterprise Modelling: Reference Architecture and Methodology", in, Molina, A., Kusiaka, A., and Sanchez, J., 1998, "Handbook of Life Cycle Engineering: Concepts, models, technologies”, Kluwer Academic Publishers, Great Britain, ISBN: 0-412-81250-9.

Mintzberg, H., 1994, “The Rise and Fall of Strategic Planning”, Prentice Hall, United Kingdom, ISBN: 0137818246

Mintzberg, H., Ahlstrand, B., and Lampel, J., 1998, "Strategic safari: the complete guide through the wilds of strategic management”, Prentice Hall, UK, ISBN: 0273656368.

Neely, A., Gregory, M. and Platts, K., 1995, "Performance Measurement System Design: a literature review and research agenda", Int. J. Operations \& Production Management, Vol. 15, No. 4, pp30-117.

O’Brien, F.A., 2003, “Scenario planning - lessons for practice from teaching and learning”, European Journal of Operations Research, vol. 152, no. 3, pp. $709-722$.

Pandya, K.V., Karlsson, A., Sega, S., and Carrie, A., 1997, “Towards the manufacturing enterprises of the future", International Journal of Operations and Production Management, Vol. 17, No., 5, pp502-521.

Pine, B.J., 1993, "Mass Customisation - the new frontier in Business Competition", Boston MA Harvard Business School Press. 
Rose, T. J., 2003, "Sustained Growth in Small Enterprises - A Process Management Approach", $\mathrm{PhD}$ Thesis, School of Industrial and Manufacturing Science, Enterprise Integration, Cranfield University, UK.

Salvendy, G., 1992, "Handbook of Industrial Engineering”, A Wiley-Interscience Publications, John Wiley \& Sons, Inc., USA, ISBN: 0-471-50276-6.

Scheer, A. W., 1994, “Business Process Engineering, Reference Models for Industrial Enterprises”, Springer-Verlag, Berlin

Scheer, A. W., 1998, “ARIS - Business Process Frameworks”, Springer-Verlag, Berlin

Seaker, R. and Wallace M. A., 1996, "Brainstorming: The common thread in TQM, empowerment, reengineering and continuous improvement." International Journal of Quality and Reliability Management, Vol. 13, no. 1, pp. $24-31$.

Shekkerman, J., 2003, "How to Survive in the Jungle of Enterprise Architecture Frameworks: Creating or Choosing an Enterprise Architecture Framework", Trafford Publishing, ISBN: 1-41201607-X.

Vernadat, F.B., "Enterprise Modelling and Integration: Principles and Applications", 1996 (Chapman \& Hall, London), ISBN 0412605503.

Warnecke, H.J., 1993, “The Fractal Company”, Springer-Verlag, Berlin. ISBN 0-387-56537.

Weston, R. H. 1999, “A model-driven, component-based approach to reconfiguring manufacturing software systems" in Special Issue on Responsiveness in Manufacturing of Int. J. of Operations and Prod. Management, Vol.19, No.8, pp 834-855.

Weston, R.H., Chatha, K.A. and Ajaefobi, J.O. 2004, Process thinking in support of systems specification and selection, Advanced Engineering Informatics, Vol. 18, Issue 4, Pages 217-229.

Williams, T.J., Bernus, P., Brosvic, J., Chen, D., Doumeingts,G., Nemes, L, Nevins, J.L., Vallespir, B., Vlietstra, J. and Zoetekouw, D. 1994. “Architectures for Integrating Manufacturing Activities and Enterprise Computers in Industry". 24/2-3. 